\title{
Edward Oczkowski* \\ Price Premiums and Discounts for Australian Sparkling Wines
}

https://doi.org/10.1515/jafio-2020-0027

Received August 6, 2020; accepted September 21, 2020

\begin{abstract}
This paper assesses the price premiums and discounts for nine sparkling wine types or names commonly employed in Australia. Hedonic wine price functions are estimated for 10 years of wine releases to identify the specific price impact of different sparkling wine types or names, after controlling for other wine price determining factors. Results identify that important price premiums occur with the use of blanc de blancs and other less common sparkling reds. An important price discount is estimated for prosecco wines. Sparkling wine type interactions with climatic regional conditions and cellaring potential also point to some interesting results. The estimates may have potentially important implications for the strategic use of wine types and names by producers and for consumers in identifying good valued sparkling wines.
\end{abstract}

Keywords: wine prices, sparkling wines, Australian wines

JEL Classification: C21, Q11, Q54

\section{Introduction}

A significant body of literature exists on estimating the relation between a wine's price and its attributes, Outreville and Le Fur (2020) identify over 100 papers which report estimates of hedonic wine price functions. Important papers in this literature initially related to the Bordeaux region (Cardebat and Figuet, 2004; Combris, Lecocq, and Visser, 1997). The bulk of the literature examines a spectrum of different wine varieties or styles to assess their relative impact on prices. In contrast, the purpose of this paper is to focus on a particular wine style, namely sparkling wines. The nature of sparkling wines is complex and involves differences in varieties employed,

Comments from an anonymous referee are gratefully acknowledged.

*Corresponding author: Edward Oczkowski, National Wine and Grape Industry Centre and School of Accounting and Finance, Charles Sturt University, PO Box 588, Wagga Wagga, NSW, 2678, Australia,

E-mail: eoczkowski@csu.edu.au production methods, sweetness styles and employed label names. This paper will unpack the relation of the use of these various types of sparkling wines with price. The analysis also recognizes the relation between these specific sparkling wine types and price may be depend on other factors such as regional climatic conditions and the wine's cellaring potential. The recognition of these potential interaction effects for a wine style on price is not commonly acknowledged in the literature.

A sparkling wine is defined as a wine which contains large amounts of carbon dioxide which produces fizz or bubbles. Carbonation is achieved through various methods, including, the bottle based méthode traditionnelle or pressured tanked based methods such as charmat (Culbert et al. 2017). Numerous types of sparkling wine exist. An important issue in this context is how do wine prices of the various types of sparkling wines differ? In particular, after controlling for wine quality differences and other factors, do particular types of sparkling wines command price premiums or discounts? Further, does the relation between sparkling wine type and price depend upon other factors? Answering these questions is important for both producers in strategically allocating resources to the most financially attractive wine types and names, and for consumers to potentially identify price bargains or over-priced wines.

This study also emphasizes the importance of the use of names on wine labels and how some wines with similar characteristics result in different prices because of the use of different wine names. Oczkowski (2018) demonstrates how different names for the same variety, for example, syrah rather than shiraz can result in significantly different Australian prices after controlling for other factors. The same issue emerges for sparkling wine where some labels contain information on the use of wine variety (e.g. chardonnay/pinot noir), degrees of sweetness (e.g. brut) or use of first pressings (cuvée), while other names or labels contain no detailed information. The study seeks to determine if the use of different names makes a difference to sparkling wine prices.

The focus of the study rests with Australian produced sparkling wines. Australia is a relatively large new world wine producer being one of the top five wine producing countries in the world (OIV 2019). Further unlike large sparkling wine regions such as French Champagne 
(appellation d'origine contrôlée, AOC), Italian Prosecco (designation of controlled origin, DOC) and Spanish Cava (denominación de origen, DO) which produce relatively homogenous wines, Australia produces a wide range of sparkling wine types from different regions with different names including the relatively unique sparkling shiraz. This variation in the use of types and names warrants a systematic analysis of any apparent price differences among Australian sparkling wines. The analysis also focuses on trends over time by assessing wine price variations over a 10 year period.

To be explicit, the purpose of the study is to estimate the price premiums or discounts associated with the use of different sparkling wine types or names for wines produced in Australia over the 10 year period 2010-2019. The analysis recognizes that the relation between wine type and price may depend on other factors such as climatic growing conditions and a wine's cellaring potential.

The Section 2 reviews some of the literature on the nature sparkling wines and their prices. Section 3 of the paper discusses the Australian sparkling wine market context, data and the methods to be employed for analysis. Section 4 presents the results from the estimated hedonic price models. Section 5 discusses the results and draws some conclusions.

\section{Literature Review}

It appears that non-carbonated still wines and sparkling wines are distinct. Official classifications of products such as the Food and Agricultural Organisation Codes (FAO), Standard International Trade Classification (SITC) and the Harmonised System Tariff System (HS) explicitly recognize the distinction between still wines and sparkling wines (Anderson, Nelgen, and Pinilla, 2017). There is some literature on consumer preferences which recognizes the special consumer attraction attributes of sparkling wines such as celebration and recalling past events (Charters 2005). Additional steps are required for the production of sparkling wines compared to still wines, such as the méthode traditionnelle, the charmat method, transfer and carbonated wines (Culbert et al. 2017). These observations suggest a distinction between still and sparkling wines may be important for any accurate analysis of price variations based on consumer tastes and costs of production.

In general the analysis of sparkling wine price variation occurs at two levels. Some studies focus on specific sparkling wine markets to examine price variations, most of these studies relate to the wines from the Champagne region. Other studies examine a wide range of wine varieties and styles and estimate hedonic price functions which include a category of sparkling wines. These latter studies are useful in assessing how sparkling wines are priced relative to other wine varieties and styles.

Gergaud (1998) estimated a hedonic price function for Champagne wines available in France during 1986-1994. Expert sensory ratings proved to be unimportant, while distribution channels and producer effects were important. In terms of designations, eight Champagne types were found to have important marginal prices. In order of importance the designations were; vintage wines; premier cru; rosé; fancy (i.e. extra quality, special, etc.); cuvée; grand cru; blanc de blancs (only using white grapes) and reserve. Bentzen and Smith (2008) examined Champagne sold in Scandinavia in 2006. Models included expert ratings (Parker and Wine Spectator) and a series of designations. Results depended upon the particular ratings employed. For Parker scores: Parker expert ratings, old vintages and full bodied were important for explaining prices. For Wine Spectator scores: Wine Spectator expert ratings and a negative influence of blanc de blancs were important. Other variables considered which were unimportant in explaining prices included brut or extra brut and blanc de noirs (only using red grapes). Lee and Sumner (2013) examined U.S. and French (not exclusively Champagne) produced sparkling wines sold in the U.S. market and assessed by Wine Spectator. Price variations were importantly impacted by Wine Spectator scores, vintage, individual U.S. and French wine regions (with Napa and Champagne being most important), over-sized bottles and a negative impact of U.S. wine labelled as Champagne.

In contrast to these studies which exclusively examine specific sparkling wine markets some studies have estimated general hedonic price functions using samples of various wine varietal/styles, including sparkling wine. ${ }^{1}$ Oczkowski (1994) using a sample of 1991 and 1992 Australian wines, estimates that sparkling wines attract a $55 \%$ premium above average wine prices, the largest of the estimated varietal/style premiums in the study. Lima (2006) uses a sample of 1995 Californian wines to estimate a price premium of $\$ 3.15$ for sparkling wines compared to the white zinfandel control. This premium represents the third largest (out of seven) variety/style price impact for the sample. Oczkowski (2010) using a sample of 2007

\footnotetext{
1 Most estimated hedonic wine price functions which employ samples covering various wine varieties/styles focus on still wines and exclude sparkling wines, see Outreville and Le Fur (2020) for a recent list of estimated hedonic functions. The implicit argument appears to be that the consumer preferences and/or production costs differ between still and sparkling wines and hence separate treatments are necessary.
} 
Australian wines divides sparkling wines into red (13\% average premium), rosé (27 \%) and white (12\%) compared to the control of shiraz. Ferro and Amaro (2018) examine the 'top 100 list' of Wine Spectator's wines over the period 2003-2016 and find that a sparkling wine dummy variable proved to be statistically insignificant and is excluded from the final preferred model. In summary, these results based on hedonic functions for a range of wine varieties/styles suggest that compared to still wines sparkling wines may attract premiums. These studies however, by design provide no definitive evidence of the relative price impacts among different types of sparkling wines.

In general, this previous literature suggests that specific types of sparkling wines may attract premiums or discounts. Types such as cuvée and blanc de blancs, vintage wines and the wine's region potentially could be important. Further, published expert ratings appear to be generally influential in explaining sparkling wine prices. This literature also indicates that while most studies have examined Champagne price variation it appears that no literature has systematically examined price differences among Australian sparkling wines.

\section{Data and Methods}

We use data from James Halliday's Australian Wine Companion (AWC) (https://www.winecompanion.com.au/) for analysing Australian sparkling wines. The AWC provides the most authoritative and comprehensive assessment of Australian wines and has been extensively used in hedonic price studies, including, Ling and Lockshin (2001), Schamel and Anderson (2003) and Oczkowski (2018). The AWC assesses approximately 9000 new releases each year, with some variation over time dependent on the wines submitted for evaluation. In terms of sparkling wines over the last 10 years (2010-2019) the number of annually assessed wines varies from 150 to over 400 , and represents $2-5 \%$ of all wines assessed. The assessed wines are typically of premium quality and cover a vast array of different types of sparkling wines, but exclude bulk wines. Among other things, the AWC provides an expert quality score out of 100 points, an indication of cellaring potential and a recommended (listed) retail price for each wine.

The wines in the sample consist of wines submitted for assessment to the AWC for any given year and are available in the market for the sample year. The total sample consists of 10 years of sample data (2010-2019). Even though for some wines the same named wine is assessed across different years, each wine is different in terms of its vintage year and/or non-vintage annual variations. In other words, the variability in the individual samples for each year reflect different named wines being assessed or the same named wines of different vintages or non-vintage variations. Given the annual variation in sample data for different assessed wines, the data is not a standard panel data set.

Sparkling wines from the AWC are initially divided into the white and red categories. Refined categories are then based on terms identified in the wine's name stated on the label. Refined categories are defined only for wines where a sufficient number of wines (10 annually) exist for analysis for the majority of years. In some cases a series of names are used on specific labels and hence some order of precedence needs to be established to uniquely classify each wine into a specific type. For sparkling white wines the following style/variety/name types are identified in the following order of precedence: ${ }^{2}$ cuvée, brut, blanc de blancs, prosecco and chardonnay/pinot noir (in either order of dominance). The remaining whites are termed sparkling white and capture numerous name types including: blanc de noirs, méthode traditionnelle, méthode champenoise, late disgorged, pinot meunier, moscato, chardonnay or no detail. For sparkling red wines the following style/variety/ name types are identified in the following order of precedence: rosé and shiraz. The remaining reds are termed sparkling red and capture numerous types including: merlot, petit verdot, durif, montepulciano, sangiovese or no detail.

The identified names and types of sparkling wines relate to a series of different features including production methods, grape varieties and sweetness levels. For production methods cuvée is commonly listed in names and refers to the first pressing of grapes and hence is expected to be of superior quality. Of lesser use in the Australian context is the identification of wines using the terms méthode traditionnelle or méthode champenoise to describe the method of production and the phrase late disgorge to describe prolonged ageing on lees. In terms of grape varieties employed there appears to be common use of the terms blanc de blancs, prosecco (the variety as opposed to the Italian region) and some combination of chardonnay and pinot noir. Other grape variety names listed but to a much lesser extent include: pinot meunier, moscato, merlot, petit verdot, durif, montepulciano and sangiovese. As a measure of sweetness, only the term brut appears to be in prominent use.

2 As examples of precedence: Yarra Burn Premium Cuvée Brut is identified as cuvée; Brown Brothers Patricia Pinot Noir Chardonnay Brut as brut, and Garbin Estate Sparkling Shiraz Rosé as rosé. 
The retail prices ${ }^{3}$ (\$AUD), expert quality scores and number of wines for the refined categories for the years 2010-2019 are presented in Table 1. Across all years, the highest average prices occur for the names/types: blanc de blancs (\$41.19), sparkling white (\$36.40) and brut (\$35.96). The lowest average prices are associated with prosecco (\$22.81), rosé (\$30) and chardonnay/pinot noir (\$30.39). These price comparisons may not be particularly meaningful as price variations may be due to quality differences for the sampled wines and not due to the use of specific names/types. Across all years the average quality scores are relatively similar and range from a low of 88.4 for prosecco to 90.1 for blanc de blancs.

Valid price and quality score comparisons over time are possibly difficult to make given the variability in the sampled wines over time. Given this recognition the following tentative observations are made. In terms of average annual price increases, brut (5.5\%), rosé $(5.1 \%)$ and sparkling white $(3.7 \%)$ had the largest increases; while blanc de blancs $(-1.0 \%)$ chardonnay/pinot noir $(0.6 \%)$ and prosecco $(1.0 \%)$ the smallest annual average price increases over time. There appears to be little variability in quality scores over time, with annual average quality point changes ranging from 0.11 points for sparkling white to -0.22 points for blanc de blancs.

To accurately estimate and identify the impact of different sparkling types or names on prices we need to recognize that many other factors also influence wine prices. Consistent with previous hedonic price models (e.g. Bekkerman and Brester 2019; Faye and Le Fur 2019; Oczkowski 2018; Schamel and Anderson 2003), in addition to the wine type/name, we consider four other wine price determinants, expert quality scores, cellaring potential, the vintage (non-vintage) of the wine and the region from where the grapes were sourced. Expert quality scores, vintage wines and the source region of grapes were found to be important in the previously cited literature on sparkling wines (Section 2).

Oczkowski and Doucouliagos (2015) have identified over 40 studies which have employed expert ratings to explain price. In part, ratings might be viewed as providing opinion leadership for consumers and/or viewed as an average measure of consumer preferences and hence potentially reflect consumer preferences for higher quality wines. Also expert ratings may also capture the higher costs in producing better quality wines and the impact of

3 There appears to be no need to adjust for general inflation effects to facilitate comparability of prices over the analysed years. For the period 2010-2018 the average annual inflation rate for retail wine products in Australia was 0.38\%, see ABS (2019). annual weather variations. ${ }^{4} \mathrm{~A}$ number of papers have pointed to the subjectivity of expert ratings and associated estimation biases in the use of single expert ratings to reflect notions of objective wine quality, see for example, Cardebat, Figuet, and Paroissien (2014) and Oczkowski (2016b). To some extent the use of the AWC and its highly expert panel members alleviates some of the inaccuracies of wine assessments. While the need to find common wines assessed by different experts to mitigate subjectivity bias, reduces samples sizes to levels where any statistical significance is unlikely to be achieved.

Cellaring potential reflects both some consumer preferences for wines which age well and the additional costs of production associated with making wines which have long cellaring potential, such as prolonged time on lees, use of oak, etc. Older vintage wines also reflect consumer tastes and the additional costs of storing and ageing wines for producers. Theoretical expectations and previous accumulated empirical evidence suggests there is an expectation that higher quality scores, longer cellaring potential and older vintages command price premiums.

The location source of grapes and regional impacts on prices in part reflect the collective reputation of producers but in the Australian context mainly reflects the suitability of long-term weather conditions for grape growing. The costs of producing grapes differ significantly between cool and warm climates in Australia (Chambers 2008; Oliver et al. 2006). For our sparkling wine samples, grapes are sourced from over 60 region or subregion Australian geographical indications (GIs). The main regions being Tasmania (12.6\% of all sampled wines), Adelaide Hills (9.8\%), Yarra Valley (8.8\%), Barossa Valley (5.7\%) and King Valley (5.5\%). Unfortunately, there are too few annual observations for the majority of regions to permit an accurate meaningful analysis of the impact of regions on prices. As an alternative, to cater for the suitability of regional climatic conditions for grape growing we classify regions and sub region GIs by long-term growing degree day (GDD) classes. Hall and Jones (2010) classify Australian GI regions into five classes based on median GDD for 30 years of data: I (GDD $\leq 1389)$; II $(1390 \leq \mathrm{GDD} \leq 1667)$; III $(1668 \leq \mathrm{GDD} \leq 1943) ; \mathrm{IV}(1944 \leq \mathrm{GDD} \leq 2221) ; \mathrm{V}(\mathrm{GDD} \geq 2222)$. The warmest class $(\mathrm{V})$ includes regions such as Riverina

4 In the Australian context for a wide variety of different quality wines Oczkowski (2016a) demonstrates how the impact of individual wine specific annual weather variations (rainfall and temperature) on prices is better modelled through expert ratings rather than as separate direct determinants of prices. In other words, expert ratings may also capture the indirect effects of annual weather variations on prices. 


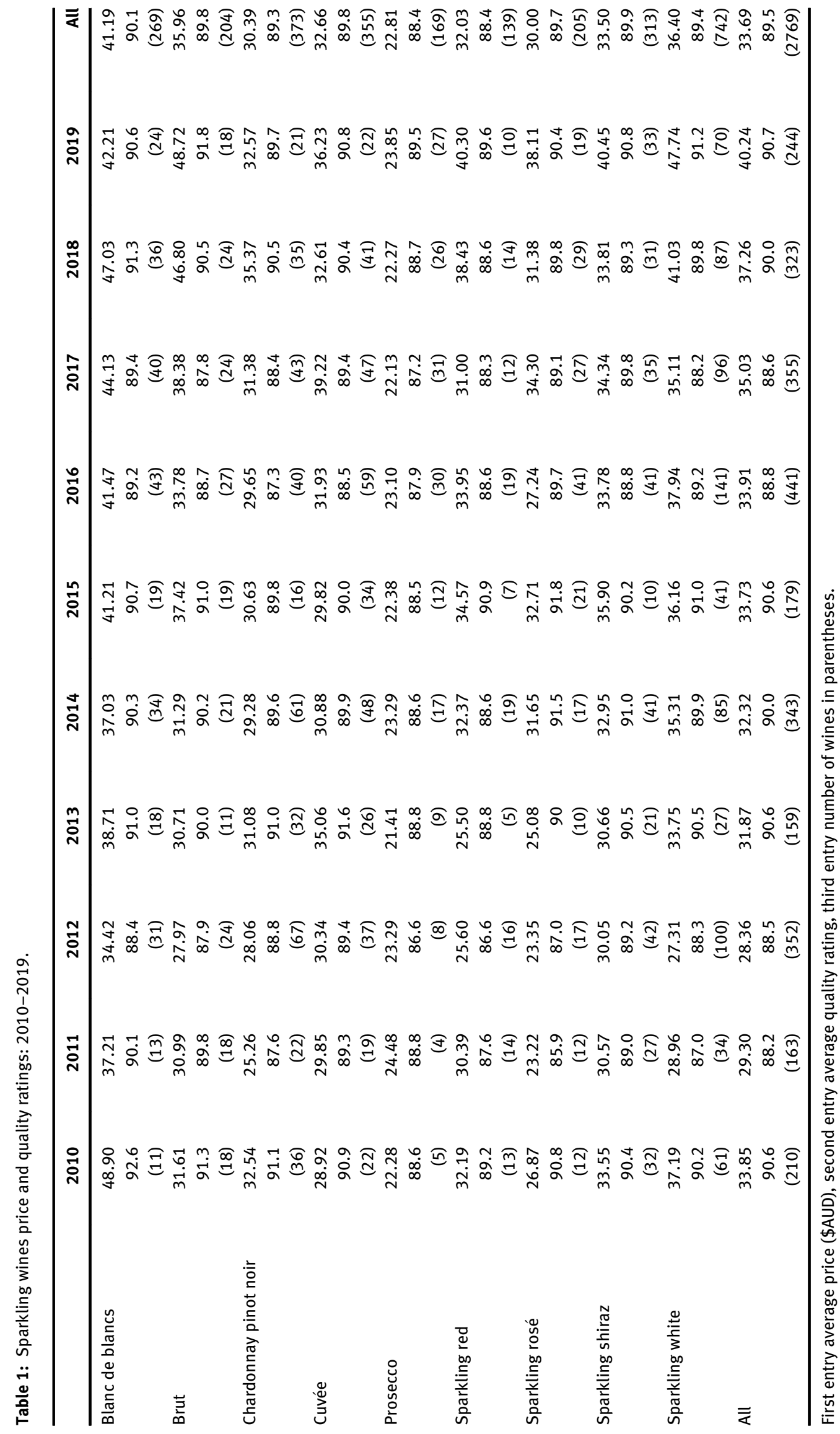


and Riverland, while the coolest class (I) includes regions such as Tasmania and Yarra Valley. In contrast to some European climates, in the Australian warm temperate climate, cool climates are preferable for growing high quality grapes and hence there is an expectation that lower GDD classes produce better quality grapes consistent with higher prices.

The modelling approach also recognizes the marginal impact of sparkling wine type on prices may depend on other factors. We explore this possibility through the use of interaction terms for sparkling wine type. Conceptually, there is an expectation that wines from particular climatic regions may impart a greater influence on the impact of sparkling wine on prices. In the Australian context, some specific sparkling wines types from cooler climates may command higher prices because of both consumer preferences and higher production costs. Also wines with longer cellaring potential may lead to higher premiums for some sparkling wine types again because of consumer preferences and higher production costs. In this case some wines are designed to be early drinking (processo), while others long-lived (shiraz) and this may affect the marginal impact of sparkling wine types on prices.

In summary, the estimated hedonic price function employs Equation (1):

$$
\begin{aligned}
\ln \left(\text { Price }_{i t}\right) & = \\
\beta_{0} & +\beta_{1}(\text { Quality Rating })_{i t}+\beta_{2}(\text { Cellar Years })_{i t} \\
& +\beta_{3}(\text { Vintage Years })_{i t} \\
& +\beta_{4}(\text { Growing Degree Days Class })_{i t} \\
& +\sum_{j=1}^{9} \beta_{5 j}(\text { Sparkling Wine Type })_{j i t} \\
& +\sum_{j=1}^{9} \beta_{6 j}(\text { Sparkling Wine Type })_{j i t} \\
& *(\text { Growing Degree Days Class })_{i t} \\
& +\sum_{j=1}^{9} \beta_{7 j}(\text { Sparkling Wine Type })_{j i t} \\
& *(\text { Cellar Years })_{i t}+\varepsilon_{i t}
\end{aligned}
$$

where, $i$ is an individual wine, $t$ is the release year of the wine, $j$ counts over nine sparkling wine types, $\beta$ s are parameters to be estimated and $\varepsilon$ is an error term. Price is the recommend retail price measured in \$AUD; Quality Rating is the score out of 100 from the AWC; Cellar Years is the number of years of cellaring potential from the release year of the AWC; Vintage Years is the age of the wine from the release year of the AWC, where zero years are allocated to a non-vintage wine; Growing Degree Days Class represents the long-term median GDD class of the grape region, sourced from Hall and Jones (2010); and Sparking Wine Type are dummy variables identifying the nine wine types/ names listed in Table 1 . The estimates associated with name/type measure any price premium or discount due to the use a specific name/type after controlling for the effects of the other variables in the estimated price function.

The use of the log-linear specification in Equation (1) is consistent with the bulk of the literature (Oczkowski and Doucouliagos 2015) and allows us to interpret estimates as approximate proportionate (percentage) effects. The sample summary statistics for the variables in Equation (1) are presented in Tables 2 and 3. The data reflect a wide range of prices averaging $\$ 34$, with some cheap wines less than $\$ 10$ and expensive wines over $\$ 300$. Quality ratings also vary significantly from below 80 points to the high 90 point range. In terms of GDD class, most wines (40.7\%) are in class II and the fewest in class V (4.3\%), with the average class score of 2.24. On average the recommended cellaring potential is 1.9 years, which for some wines extends up to 40 years. The average number of vintage years is 2.6 with approximately $37 \%$ non-vintage wines (vintage years set to zero).

In addition to Table 1, Table 3 reports more summary statistics for the sparkling wine types. In terms of GDD class, on average sparkling shiraz and sparkling red are grown in the warmest climatic regions, while blanc de blancs and sparkling rosé in the coolest regions. Sparkling shiraz has on average the longest cellar years and prosecco the shortest. In terms of vintage years, blanc de blancs and brut have the longest years, while prosecco stands out as having the shortest years.

The correlation among the main variables are presented in Table 4. All correlations are low or moderate and none of the correlations for non-price variables exceed 0.5, indicating relative low degrees of potential multicollinearity. The correlations with price are as expected with higher prices associated with cooler climates and longer cellaring and vintage years.

Given the use of dummy variables for wine names/types in Equation (1), rather than use an omitted control group for dummy variables we estimate marginal effects as deviations from average prices. We follow Kennedy (1986) as implemented by Oczkowski (1994, p100), to estimate coefficients for all dummy variables, and interpret marginal estimates as deviations from the mean of the dependent variable when 
Table 2: Descriptive statistics.

\begin{tabular}{lrrrr}
\hline & Mean & Std Dev & Min & Max \\
\hline Price (\$AUD) & 33.69 & 18.88 & 4.60 & 350 \\
Ln (price) & 3.41 & 0.44 & 1.53 & 5.86 \\
Quality rating & 89.5 & 3.41 & 79 & 99 \\
Growing degree days (class) & 2.24 & 1.01 & 1 & 5 \\
Cellaring years & 1.90 & 2.59 & -1 & 40 \\
Vintage years & 2.63 & 2.96 & 0 & 20 \\
\hline
\end{tabular}

$n=2769$, all years 2010-2019.

Table 3: Sparkling wines descriptive statistics.

\begin{tabular}{lrrr}
\hline & $\begin{array}{r}\text { Growing degree days } \\
\text { class }\end{array}$ & $\begin{array}{r}\text { Cellar } \\
\text { years }\end{array}$ & $\begin{array}{r}\text { Vintage } \\
\text { years }\end{array}$ \\
\hline Blanc de blancs & 1.974 & 2.554 & 3.717 \\
& $(0.956)$ & $(3.113)$ & $(2.790)$ \\
Brut & 2.191 & 1.931 & 3.216 \\
& $(1.016)$ & $(2.260)$ & $(3.338)$ \\
Chardonnay pinot & 2.247 & 1.697 & 2.828 \\
noir & $(1.002)$ & $(1.855)$ & $(2.847)$ \\
Cuvée & 2.002 & 1.442 & 2.428 \\
& $(1.141)$ & $(2.043)$ & $(2.995)$ \\
Prosecco & 2.379 & 0.426 & 0.692 \\
& $(0.823)$ & $(0.737)$ & $(0.764)$ \\
Sparkling red & 2.741 & 2.295 & 1.906 \\
& $(0.863)$ & $(2.682)$ & $(2.242)$ \\
Sparkling rosé & 1.990 & 1.224 & 1.941 \\
& $(1.076)$ & $(1.574)$ & $(2.695)$ \\
Sparkling shiraz & 2.719 & 3.492 & 2.429 \\
& $(0.723)$ & $(4.328)$ & $(3.040)$ \\
Sparkling white & 2.190 & 1.801 & 2.912 \\
& $(1.026)$ & $(2.297)$ & $(3.122)$ \\
\hline
\end{tabular}

$\mathrm{n}=2769$, all years 2010-2019. Means presented. Standard deviation in parentheses.

Table 4: Correlations.

\begin{tabular}{lrrrrr}
\hline & (1) & (2) & (3) & (4) & (5) \\
\hline (1) Price (\$AUD) & 1.0 & & & & \\
(2) Ln (price) & 0.889 & 1.0 & & & \\
(3) Quality rating & 0.466 & 0.544 & 1.0 & & \\
(4) Growing degree days & -0.320 & -0.430 & -0.402 & 1.0 & \\
(class) & & & & & \\
(5) Cellaring years & 0.337 & 0.382 & 0.394 & -0.140 & 1.0 \\
(6) Vintage years & 0.567 & 0.597 & 0.411 & -0.257 & 0.259 \\
\hline
\end{tabular}

$\mathrm{n}=2769$, all years $2010-2019$.

the other (non-dummy) variables are measured at their means. In other words, the estimate for a specific sparkling wine type is the approximate percentage deviation from the mean sample wine price.

\section{Empirical Results}

For Equation (1) we examined interactions among sparkling wine types and all four independent variables: quality rating, GDD class, cellar years and vintage years. Invariably, most statistically significant interaction effects occurred with GDD class and cellar years. Adding quality rating and vintage years interactions did not substantially increase the number of significant variables, which in part, is due to the additional large number of parameters to be estimated and sample size limitations. The estimates for Equation (1) for each of the 10 years (2010-2019) and all years combined ${ }^{5}$ are presented in Tables 5 and 6 . Estimates recognize heteroscedasticity in error terms by employing heteroscedastic robust standard errors.

The RESET specification error test indicates the loglinear functional form is not rejected for all individual years except for 2011-2013 (where only 2013 is significant at a 5\% level). In contrast, the RESET specification error test rejects the linear form for all years except 2016. The goodness of fit of models is acceptable for cross section data and varies from 54.7 to $69.5 \%$ explained variation. The robust Chow test statistic which tests for the statistical equality of parameters across all years is $3.94 \sim \mathrm{F}(63,2677)$ with $p<0.0001$. This indicates that there is significant variation among the yearly estimates and that the estimates for all years combined is presented for completeness only.

We performed a series of robustness checks to establish the veracity of the presented estimates and indicate that other modelling options were explicitly considered in developing the preferred estimates. The robustness checks relate to procedures and variables used in other hedonic wine price studies and include: the use of quantile regression, alternative definitions of variables and producer and region fixed effects. Quantile regression models were estimated using the 25,50 and $75 \%$ quartiles for prices and the specification which excludes interaction terms. ${ }^{6}$ Of the 90 bootstrap $\mathrm{F}$ tests for testing the equivalence of quartile estimates, (one test for each wine type/name wine year combination), only two ( $2.2 \%$ of all tests) indicated statistical differences at the $5 \%$ level of significance. This results points to the constancy of the estimated premiums and discounts across different price segments.

5 The model with all years combined includes yearly dummy variables to account for any inflation effects.

6 Including interaction terms in the quantile regression models proved to be unsuccessful as in many cases the degrees of freedom were too few leading to estimation non-convergence problems. 
Table 5: Sparkling wines hedonic wine price estimates: 2010-2014.

\begin{tabular}{|c|c|c|c|c|c|}
\hline & 2010 & 2011 & 2012 & 2013 & 2014 \\
\hline \multicolumn{6}{|l|}{ Sparkling wine type } \\
\hline \multirow[t]{2}{*}{ Blanc de blancs } & -0.098 & $0.221^{\star}$ & 0.005 & $0.323^{\star \star}$ & -0.035 \\
\hline & $(-1.13)$ & $(1.66)$ & $(0.04)$ & $(2.46)$ & $(-0.33)$ \\
\hline \multirow[t]{2}{*}{ Brut } & 0.367 & 0.291 & -0.121 & 0.171 & 0.014 \\
\hline & $(1.55)$ & $(1.42)$ & $(-0.52)$ & $(1.12)$ & $(0.11)$ \\
\hline \multirow[t]{2}{*}{ Chardonnay pinot noir } & $-0.225^{\star \star}$ & -0.232 & 0.141 & -0.106 & $0.184^{\star \star}$ \\
\hline & $(-2.14)$ & $(-1.47)$ & $(1.10)$ & $(-0.89)$ & $(2.07)$ \\
\hline \multirow[t]{2}{*}{ Cuvée } & -0.246 & -0.014 & 0.197 & 0.042 & 0.022 \\
\hline & $(-1.61)$ & $(-0.07)$ & $(1.25)$ & $(0.34)$ & $(0.15)$ \\
\hline \multirow[t]{2}{*}{ Prosecco } & 0.143 & -0.051 & $-0.345^{\star \star \star}$ & -0.163 & $-0.215^{\star \star}$ \\
\hline & $(0.58)$ & $(-0.64)$ & $(-2.58)$ & $(-1.45)$ & $(-2.02)$ \\
\hline \multirow[t]{2}{*}{ Sparkling red } & 0.379 & 0.054 & 0.119 & 0.445 & -0.157 \\
\hline & $(1.42)$ & $(0.14)$ & $(0.47)$ & $(0.66)$ & $(-1.17)$ \\
\hline \multirow[t]{2}{*}{ Sparkling rosé } & -0.076 & -0.047 & -0.045 & -0.062 & $-0.218^{\star \star \star}$ \\
\hline & $(-0.47)$ & $(-0.20)$ & $(-0.35)$ & $(-0.16)$ & $(-2.70)$ \\
\hline \multirow[t]{2}{*}{ Sparkling shiraz } & -0.241 & 0.069 & $-0.300^{\star}$ & -0.232 & $-0.441^{\star \star \star}$ \\
\hline & $(-1.38)$ & $(0.44)$ & $(-1.68)$ & $(-1.45)$ & $(-3.24)$ \\
\hline \multirow[t]{2}{*}{ Sparkling white } & $0.180^{\star}$ & -0.135 & -0.010 & -0.025 & $0.201^{\star \star}$ \\
\hline & $(1.79)$ & $(-0.77)$ & $(-0.14)$ & $(-0.09)$ & $(1.97)$ \\
\hline \multicolumn{6}{|c|}{ Sparkling wine type ${ }^{*} G D D$ class } \\
\hline \multirow[t]{2}{*}{ Blanc de blancs } & $0.294^{\star \star \star}$ & $-0.106^{\star}$ & 0.072 & -0.089 & $0.090^{\star \star \star}$ \\
\hline & $(4.29)$ & $(-1.86)$ & $(1.16)$ & $(-1.04)$ & $(2.61)$ \\
\hline \multirow[t]{2}{*}{ Brut } & $-0.134^{\star \star \star}$ & -0.095 & 0.027 & 0.017 & -0.022 \\
\hline & $(-2.87)$ & $(-1.32)$ & $(0.33)$ & $(0.35)$ & $(-0.52)$ \\
\hline \multirow[t]{2}{*}{ Chardonnay pinot noir } & -0.10 & 0.013 & -0.035 & 0.052 & $-0.083^{* \star}$ \\
\hline & $(-0.36)$ & $(0.26)$ & $(-0.88)$ & $(1.41)$ & $(-2.55)$ \\
\hline \multirow[t]{2}{*}{ Cuvée } & -0.032 & 0.035 & -0.087 & -0.051 & $-0.116^{\star \star}$ \\
\hline & $(-0.78)$ & $(0.52)$ & $(-1.60)$ & $(-1.35)$ & $(-2.51)$ \\
\hline \multirow[t]{2}{*}{ Prosecco } & $-0.248^{\star \star \star}$ & & $0.092^{\star}$ & 0.021 & $0.072^{*}$ \\
\hline & $(-2.94)$ & & $(1.96)$ & $(0.57)$ & $(1.94)$ \\
\hline \multirow[t]{2}{*}{ Sparkling red } & -0.112 & -0.068 & -0.049 & -0.092 & 0.072 \\
\hline & $(-1.63)$ & $(-0.38)$ & $(-0.61)$ & $(-0.96)$ & $(1.44)$ \\
\hline \multirow[t]{2}{*}{ Sparkling rosé } & 0.028 & -0.098 & 0.009 & -0.065 & $0.102^{\star \star}$ \\
\hline & $(0.72)$ & $(-1.55)$ & $(0.24)$ & $(-0.85)$ & $(2.21)$ \\
\hline Sparkling shiraz & $0.153^{\star *}$ & 0.036 & $0.112^{\star}$ & 0.069 & $0.174^{\star \star \star}$ \\
\hline & $(2.34)$ & $(0.64)$ & $(1.72)$ & $(1.35)$ & (3.69) \\
\hline Sparkling white & -0.038 & $0.096^{*}$ & -0.016 & 0.019 & -0.040 \\
\hline & $(-1.18)$ & $(1.83)$ & $(-0.66)$ & $(0.26)$ & $(-0.91)$ \\
\hline Sparkling wine type ${ }^{*} c$ & & & & & \\
\hline Blanc de blancs & -0.043 & -0.009 & 0.002 & -0.004 & -0.008 \\
\hline & $(-1.13)$ & $(-0.17)$ & $(0.08)$ & $(-0.07)$ & $(-0.35)$ \\
\hline Brut & -0.046 & $-0.070^{\star}$ & 0.038 & $-0.098^{\star \star \star}$ & 0.034 \\
\hline & $(-0.97)$ & $(-1.71)$ & $(0.96)$ & $(-3.29)$ & $(1.36)$ \\
\hline Chardonnay pinot noir & $0.045^{\star \star}$ & 0.066 & -0.060 & -0.022 & -0.025 \\
\hline & $(2.02)$ & $(1.51)$ & $(-1.47)$ & $(-0.59)$ & $(-1.52)$ \\
\hline Cuvée & $0.074^{\star \star \star}$ & -0.046 & -0.033 & 0.020 & $0.081^{\star \star}$ \\
\hline & $(2.08)$ & $(-1.01)$ & $(-0.80)$ & $(0.42)$ & $(2.35)$ \\
\hline Prosecco & 0.106 & 0.047 & $0.105^{\star \star}$ & $0.107^{\star \star}$ & -0.095 \\
\hline & $(1.32)$ & $(0.68)$ & $(2.56)$ & $(2.18)$ & $(-1.20)$ \\
\hline Sparkling red & 0.001 & 0.072 & 0.029 & -0.162 & 0.043 \\
\hline & $(0.01)$ & $(0.62)$ & $(0.73)$ & $(-0.63)$ & $(1.50)$ \\
\hline Sparkling rosé & -0.026 & 0.167 & -0.007 & 0.066 & 0.016 \\
\hline & $(-0.72)$ & $(1.28)$ & $(-0.11)$ & $(0.37)$ & $(0.84)$ \\
\hline Sparkling shiraz & $-0.044^{\star \star \star}$ & $-0.080^{\star \star}$ & 0.029 & 0.010 & $-0.018^{\star}$ \\
\hline & $(-2.75)$ & $(-2.39)$ & $(1.07)$ & $(0.34)$ & $(-1.70)$ \\
\hline
\end{tabular}


Table 5: (continued)

\begin{tabular}{|c|c|c|c|c|c|}
\hline & 2010 & 2011 & 2012 & 2013 & 2014 \\
\hline \multirow[t]{2}{*}{ Sparkling white } & -0.012 & -0.007 & 0.016 & 0.012 & -0.018 \\
\hline & $(-0.58)$ & $(-0.14)$ & $(0.73)$ & $(0.14)$ & $(-1.43)$ \\
\hline \multirow[t]{2}{*}{ Quality rating } & $0.052^{\star \star \star}$ & $0.033^{\star \star \star}$ & $0.029^{\star \star \star}$ & $0.056^{\star * *}$ & $0.029^{\star \star \star}$ \\
\hline & $(3.25)$ & $(3.11)$ & $(4.26)$ & $(4.53)$ & $(5.60)$ \\
\hline \multirow[t]{2}{*}{ GDD class } & $-0.052^{\star \star \star}$ & $-0.069 \star \star$ & $-0.088^{\star \star \star}$ & $-0.075^{\star \star \star}$ & $-0.090^{\star \star \star}$ \\
\hline & $(-2.82)$ & $(-2.37)$ & $(-4.42)$ & $(-2.74)$ & $(-4.75)$ \\
\hline \multirow[t]{2}{*}{ Cellaring years } & $0.056^{\star \star \star}$ & $0.074^{\star \star \star}$ & 0.021 & 0.024 & $0.035^{\star \star \star}$ \\
\hline & $(4.46)$ & $(3.35)$ & $(1.36)$ & $(0.87)$ & (3.49) \\
\hline \multirow[t]{2}{*}{ Vintage years } & $0.051^{\star \star \star}$ & $0.049^{\star \star \star}$ & $0.057^{\star \star \star}$ & $0.028^{\star \star}$ & $0.049^{\star \star \star}$ \\
\hline & $(5.55)$ & $(4.32)$ & $(7.74)$ & $(2.02)$ & $(6.44)$ \\
\hline \multirow[t]{2}{*}{ Constant } & -1.437 & 0.278 & 0.744 & -1.685 & $0.786^{*}$ \\
\hline & $(-1.02)$ & $(0.30)$ & (1.35) & $(-1.50)$ & $(1.70)$ \\
\hline$R^{2}$ & 0.587 & 0.626 & 0.547 & 0.695 & 0.649 \\
\hline RESET(2) & -0.05 & $-2.47^{\star \star}$ & $-1.66^{*}$ & $-1.75^{\star}$ & -1.21 \\
\hline $\mathrm{N}$ & 210 & 163 & 352 & 159 & 343 \\
\hline
\end{tabular}

$\star \star \star \star * \star * ~ *$ denotes statistically significant at the 1, 5 and $10 \%$ levels respectively. Dependent variable is the log of price. Robust t-ratios reported in parentheses. RESET (2) is the robust Ramsey specification error test using the squared predictions.

A series of dummy variables for wine vintage and nonvintage wines were examined given the high number of nonvintage wines. Non-vintage wines were found to be cheaper than vintage wines and a linear specification for vintage years proved to be appropriate, setting non-vintage wines to zero. The use of the linear specification was empirically superior to the use of dummy variables for vintage and nonvintage. We also examined alternative measures of the climatic effect of regions. Rather than use GDD class, the actual number of long-term median GDD was employed directly and in quadratic form. Both alternative specifications proved empirically inferior to the use of GDD class. When employed in quadratic form GDD and $\mathrm{GDD}^{2}$ were both statistically insignificant. It is important to recognize that GDD class is a long-term measure of climate which captures the effects of regions on prices given the use of regions directly is not possible because of data size limitations.

The use of producer and region fixed effects proved to be unsuccessful, their use led to significant estimation efficiency problems for the main regressors due to the large number of producers (on average 1.49 wines per producer) and regions (on average 5.2 wines per region). For the producer effects model, GDD class and cellar years are insignificant for all years, and quality is insignificant for nine years. For the region effects model, as expected GDD class is insignificant in seven years, and cellar years in four years. For both fixed effects models the number of significant sparkling wine types is reduced substantially.

Given the use of interactions terms in our preferred specification, the total impact of a sparkling wine type on prices depends on both GDD class and cellar years. In
Tables 7 and 8, we present the estimates of the total impact of sparkling wine type on prices evaluated at the means of the data for GDD class and cellar years. Appropriate robust Wald tests are employed to evaluate the statistical significance of these total effects. The estimates for the wine name/types exhibit variability across years for some specific wine types but also exhibit some consistent patterns for other types.

Employing total marginal estimates from Tables 7 and 8 , in broad terms over the 10 years two wine types have important price premiums, blanc de blancs (10.3\% yearly average or $\$ 3.60$ at mean prices) and sparkling red (8.5\% average, or $\$ 2.86$ at mean prices). Only one wine type has a relatively a large price discount: prosecco $(-10.7 \%$ average, $-\$ 3.60$ at mean prices). Sparkling white has a moderate positive price impact $(4.8 \%$ average or $\$ 1.62$ at mean prices). Three sparkling wine types have a moderate negative impact: cuvée $(-5.9 \%,-\$ 1.99$ at mean prices), chardonnay/pinot noir $(-5.6 \%,-\$ 1.89$ at mean prices) and rosé $(-5.2 \%,-\$ 1.75$ at mean prices). Two sparkling wine types have prices reasonably similar to average prices: brut $(2.6 \%, \$ 0.88$ at mean prices) and shiraz (1.5\% average, $\$ 0.51$ at mean prices).

A number of individual yearly estimates have important price discounts/premiums which exceed 10\%. Individual year price premiums which exceed $10 \%$ are estimated for: blanc de blancs (six years), sparkling red (three years), sparkling white (one year) and brut (one year). Individual year price discounts which exceed $10 \%$ are estimated for: prosecco (five years), cuvée (four years), rosé (three years) and chardonnay/pinot noir (two years). 
Table 6: Sparkling wines hedonic wine price estimates: 2015-2019.

\begin{tabular}{|c|c|c|c|c|c|c|}
\hline & 2015 & 2016 & 2017 & 2018 & 2019 & 2010-2019 \\
\hline \multicolumn{7}{|l|}{ Sparkling wine type } \\
\hline \multirow[t]{2}{*}{ Blanc de blancs } & 0.259 & 0.079 & $0.293^{\star \star \star}$ & 0.186 & $0.278^{\star \star}$ & $0.121^{\star \star \star}$ \\
\hline & $(1.25)$ & $(0.84)$ & (3.23) & $(1.57)$ & $(2.36)$ & (2.93) \\
\hline \multirow[t]{2}{*}{ Brut } & 0.248 & 0.162 & $0.378^{\star \star}$ & $0.608^{\star \star}$ & -0.079 & $0.226^{\star \star \star}$ \\
\hline & $(1.62)$ & $(1.04)$ & $(2.44)$ & $(2.21)$ & $(-0.51)$ & $(4.43)$ \\
\hline \multirow[t]{2}{*}{ Chardonnay pinot noir } & -0.034 & -0.052 & -0.028 & -0.059 & -0.039 & $-0.066^{\star}$ \\
\hline & $(-0.26)$ & $(-0.52)$ & $(-0.35)$ & $(-0.48)$ & $(-0.24)$ & $(-1.90)$ \\
\hline \multirow[t]{2}{*}{ Cuvée } & 0.114 & $0.207^{\star \star}$ & $0.166^{\star}$ & -0.007 & 0.098 & $0.090^{\star \star}$ \\
\hline & $(1.05)$ & $(2.02)$ & $(1.72)$ & $(-0.06)$ & $(0.97)$ & $(2.34)$ \\
\hline \multirow[t]{2}{*}{ Prosecco } & -0.115 & $-0.259^{\star}$ & 0.051 & $-0.498^{\star \star \star}$ & -0.138 & $-0.154^{\star \star \star}$ \\
\hline & $(-1.29)$ & $(-1.78)$ & $(0.70)$ & $(-3.04)$ & $(-1.28)$ & $(-2.72)$ \\
\hline \multirow[t]{2}{*}{ Sparkling red } & -0.067 & -0.356 & $-1.381^{\star \star}$ & $-0.432^{\star \star}$ & $0.636^{\star \star \star}$ & -0.034 \\
\hline & $(-0.22)$ & $(-1.22)$ & $(-2.33)$ & $(-2.22)$ & (3.14) & $(-0.37)$ \\
\hline \multirow[t]{2}{*}{ Sparkling rosé } & -0.055 & -0.152 & 0.156 & 0.191 & 0.007 & -0.002 \\
\hline & $(-0.34)$ & $(-1.55)$ & $(1.08)$ & $(1.60)$ & $(0.06)$ & $(-0.04)$ \\
\hline \multirow[t]{2}{*}{ Sparkling shiraz } & -0.567 & -0.165 & $-0.693^{\star \star \star}$ & -0.178 & $-0.477^{\star}$ & 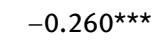 \\
\hline & $(-1.21)$ & $(-1.08)$ & $(-4.57)$ & $(-1.39)$ & $(-1.76)$ & $(-4.50)$ \\
\hline \multirow[t]{2}{*}{ Sparkling white } & -0.104 & 0.068 & 0.076 & 0.001 & 0.091 & 0.036 \\
\hline & $(-1.05)$ & $(1.11)$ & $(1.24)$ & $(0.01)$ & $(0.95)$ & $(1.30)$ \\
\hline \multicolumn{7}{|c|}{ Sparkling wine type ${ }^{*} G D D$ class } \\
\hline \multirow[t]{2}{*}{ Blanc de blancs } & -0.068 & 0.028 & -0.042 & -0.038 & $-0.150 \star \star \star$ & 0.005 \\
\hline & $(-0.76)$ & $(0.77)$ & $(-1.29)$ & $(-0.96)$ & $(-2.64)$ & $(0.26)$ \\
\hline \multirow[t]{2}{*}{ Brut } & -0.034 & -0.062 & $-0.126^{\star *}$ & $-0.177^{\star \star}$ & $0.129 * \star$ & $-0.067^{\star \star \star}$ \\
\hline & $(-0.39)$ & $(-1.30)$ & $(-2.20)$ & $(-1.98)$ & (1.98) & $(-3.47)$ \\
\hline \multirow[t]{2}{*}{ Chardonnay pinot noir } & $-0.061^{*}$ & -0.002 & -0.003 & $-0.041^{*}$ & -0.052 & 0.001 \\
\hline & $(-1.66)$ & $(-0.04)$ & $(-0.10)$ & $(-1.78)$ & $(-0.91)$ & $(0.10)$ \\
\hline \multirow[t]{2}{*}{ Cuvée } & $-0.097^{\star \star}$ & $-0.142^{\star \star \star}$ & $-0.093^{\star *}$ & -0.057 & $-0.084^{\star \star}$ & $-0.085^{\star \star \star}$ \\
\hline & $(-2.20)$ & $(-3.30)$ & $(-2.05)$ & $(-1.24)$ & $(-2.07)$ & $(-5.25)$ \\
\hline \multirow[t]{2}{*}{ Prosecco } & 0.018 & 0.064 & $-0.073^{\star * \star}$ & 0.068 & -0.031 & 0.008 \\
\hline & $(0.65)$ & $(1.08)$ & $(-2.73)$ & $(1.53)$ & $(-0.87)$ & $(0.34)$ \\
\hline \multirow{2}{*}{ Sparkling red } & 0.112 & $0.172^{*}$ & $0.380^{\star \star}$ & $0.179^{\star \star \star}$ & $-0.150^{\star}$ & 0.034 \\
\hline & $(0.65)$ & $(1.76)$ & $(2.17)$ & $(2.64)$ & $(-1.86)$ & $(1.08)$ \\
\hline \multirow[t]{2}{*}{ Sparkling rosé } & 0.049 & 0.026 & -0.060 & -0.051 & -0.018 & -0.017 \\
\hline & $(0.70)$ & $(0.78)$ & $(-0.94)$ & $(-1.40)$ & $(-0.40)$ & $(-0.82)$ \\
\hline Sparkling shiraz & 0.284 & 0.081 & $0.279^{\star \star \star}$ & 0.058 & $0.247^{\star \star}$ & $0.121^{\star * *}$ \\
\hline & (1.41) & $(1.48)$ & $(5.43)$ & $(1.15)$ & $(2.31)$ & $(5.79)$ \\
\hline Sparkling white & 0.033 & -0.005 & -0.013 & 0.014 & -0.018 & 0.002 \\
\hline & $(0.88)$ & $(-0.20)$ & $(-0.50)$ & $(0.51)$ & $(-0.44)$ & $(0.15)$ \\
\hline Sparkling wine type ${ }^{*} c$ & ars & & & & & \\
\hline Blanc de blancs & 0.004 & -0.007 & $-0.050^{\star \star \star}$ & 0.001 & $0.074^{\star \star \star}$ & $-0.009^{\star}$ \\
\hline & $(0.20)$ & $(-0.60)$ & $(-3.22)$ & $(0.03)$ & (3.97) & $(-1.67)$ \\
\hline Brut & -0.026 & -0.020 & -0.017 & $-0.090^{\star \star}$ & $-0.044^{\star \star}$ & $-0.025^{\star \star \star}$ \\
\hline & $(-1.14)$ & $(-1.26)$ & $(-1.01)$ & $(-1.96)$ & $(-2.32)$ & $(-3.42)$ \\
\hline Chardonnay pinot noir & $0.075^{\star \star \star}$ & 0.020 & -0.021 & $-0.041^{\star}$ & 0.012 & 0.011 \\
\hline & (3.03) & $(1.20)$ & $(-0.80)$ & $(-1.78)$ & $(0.28)$ & $(1.43)$ \\
\hline Cuvée & 0.012 & $0.025^{*}$ & $0.065^{\star \star}$ & 0.008 & 0.010 & $0.018^{\star \star}$ \\
\hline & $(0.68)$ & $(1.82)$ & $(2.53)$ & $(0.39)$ & $(0.60)$ & $(2.46)$ \\
\hline Prosecco & $-0.173^{\star}$ & 0.033 & 0.028 & $0.178^{\star \star}$ & -0.010 & -0.004 \\
\hline & $(-1.92)$ & $(0.38)$ & $(0.72)$ & $(2.08)$ & $(-0.27)$ & $(-0.20)$ \\
\hline Sparkling red & -0.053 & -0.009 & $0.282^{\star \star}$ & 0.022 & 0.019 & 0.013 \\
\hline & $(-1.07)$ & $(-0.67)$ & (2.33) & $(0.80)$ & $(0.84)$ & (1.12) \\
\hline Sparkling rosé & -0.016 & -0.030 & $-0.045^{\star \star \star}$ & $-0.054^{\star}$ & 0.003 & -0.011 \\
\hline & $(-0.47)$ & $(-0.92)$ & $(-3.55)$ & $(-1.73)$ & $(0.09)$ & $(-1.34)$ \\
\hline Sparkling shiraz & -0.008 & -0.007 & -0.019 & -0.003 & $-0.034^{\star \star}$ & $-0.012^{\star \star \star}$ \\
\hline & $(-0.37)$ & $(-0.61)$ & $(-0.95)$ & $(-0.24)$ & $(-2.54)$ & $(-2.97)$ \\
\hline
\end{tabular}


Table 6: (continued)

\begin{tabular}{|c|c|c|c|c|c|c|}
\hline & 2015 & 2016 & 2017 & 2018 & 2019 & 2010-2019 \\
\hline \multirow[t]{2}{*}{ Sparkling white } & $0.041^{\star *}$ & -0.005 & -0.022 & -0.001 & -0.004 & 0.002 \\
\hline & $(2.46)$ & $(-0.42)$ & $(-1.48)$ & $(-0.01)$ & $(-0.16)$ & $(0.15)$ \\
\hline \multirow[t]{2}{*}{ Quality rating } & $0.031^{\star \star}$ & $0.023^{\star \star \star}$ & 0.007 & $0.027^{\star \star \star}$ & $0.030^{\star \star}$ & $0.027^{\star \star \star}$ \\
\hline & $(2.46)$ & (4.14) & (1.09) & $(4.06)$ & $(2.24)$ & (11.8) \\
\hline \multirow[t]{2}{*}{ GDD class } & $-0.073^{\star \star}$ & $-0.085^{\star \star \star}$ & $-0.086^{\star \star \star}$ & $-0.057^{\star \star \star}$ & $-0.103^{\star \star \star}$ & $-0.083^{\star \star \star}$ \\
\hline & $(-2.57)$ & $(-5.33)$ & $(-5.29)$ & $(-3.07)$ & $(-3.89)$ & $(-12.6)$ \\
\hline \multirow[t]{2}{*}{ Cellaring years } & 0.014 & $0.023^{\star \star}$ & $0.049^{\star \star \star}$ & $0.031^{\star \star \star}$ & $0.049^{\star \star \star}$ & $0.028^{\star \star \star}$ \\
\hline & $(0.98)$ & $(2.43)$ & $(4.49)$ & $(2.87)$ & $(3.59)$ & $(8.64)$ \\
\hline \multirow[t]{2}{*}{ Vintage years } & $0.045^{\star \star \star}$ & $0.058^{\star \star \star}$ & $0.064^{\star \star \star}$ & $0.059^{\star \star \star}$ & $0.068^{\star \star \star}$ & $0.057^{\star \star \star}$ \\
\hline & (4.37) & (7.38) & (10.5) & $(7.04)$ & $(7.87)$ & (21.6) \\
\hline \multirow[t]{2}{*}{ constant } & 0.628 & $1.377^{\star \star \star}$ & $2.784^{\star \star \star}$ & 0.937 & $1.712^{\star \star}$ & $0.876^{\star \star \star}$ \\
\hline & $(0.55)$ & $(2.81)$ & (4.87) & $(1.55)$ & $(2.09)$ & $(4.16)$ \\
\hline $\mathrm{R}^{2}$ & 0.568 & 0.586 & 0.628 & 0.600 & 0.650 & 0.581 \\
\hline RESET(2) & -0.13 & -0.37 & -0.88 & 1.51 & -0.95 & -0.89 \\
\hline $\mathrm{N}$ & 179 & 441 & 355 & 323 & 244 & 2769 \\
\hline
\end{tabular}

$\star \star \star \star * \star * ~ *$ denotes statistically significant at the 1, 5 and $10 \%$ levels respectively. Dependent variable is the log of price. Robust t-ratios reported in parentheses. RESET (2) is the robust Ramsey specification error test using the squared predictions. Estimates for pooled data (2010-2019) include time dummies for year of release.

Table 7: Total sparkling wine type effect on prices: 2010-2014.

\begin{tabular}{|c|c|c|c|c|c|}
\hline & 2010 & 2011 & 2012 & 2013 & 2014 \\
\hline \multirow[t]{2}{*}{ Blanc de blancs } & 0.090 & 0.020 & $0.162^{\star \star \star}$ & $0.128^{*}$ & $0.137^{\star \star \star}$ \\
\hline & $(1.35)$ & $(0.10)$ & $(13.4)$ & $(3.84)$ & (17.3) \\
\hline \multirow[t]{2}{*}{ Brut } & -0.069 & -0.061 & -0.002 & $0.090^{\star \star}$ & 0.020 \\
\hline & $(1.85)$ & $(1.23)$ & $(0.01)$ & $(3.92)$ & $(0.15)$ \\
\hline \multirow[t]{2}{*}{ Chardonnay pinot noir } & $-0.125^{\star \star \star}$ & -0.070 & -0.018 & -0.037 & -0.042 \\
\hline & (10.1) & $(1.30)$ & $(0.29)$ & $(0.98)$ & $(2.22)$ \\
\hline \multirow[t]{2}{*}{ Cuvée } & $-0.132^{\star \star \star}$ & -0.005 & -0.029 & -0.028 & $-0.117^{\star \star \star}$ \\
\hline & (9.93) & $(0.01)$ & $(0.49)$ & $(0.26)$ & $(6.93)$ \\
\hline \multirow{2}{*}{ Prosecco } & $-0.113^{\star \star}$ & -0.027 & -0.036 & -0.070 & $-0.071^{\star}$ \\
\hline & (3.95) & $(0.07)$ & $(0.51)$ & $(0.192)$ & (3.24) \\
\hline \multirow[t]{2}{*}{ Sparkling red } & 0.097 & 0.027 & 0.030 & -0.038 & $0.123^{\star \star}$ \\
\hline & $(2.13)$ & $(0.09)$ & $(0.27)$ & $(0.14)$ & $(5.19)$ \\
\hline \multirow[t]{2}{*}{ Sparkling rosé } & -0.077 & -0.104 & -0.032 & $-0.145^{\star}$ & -0.023 \\
\hline & $(1.82)$ & $(1.14)$ & $(0.49)$ & $(3.05)$ & $(0.48)$ \\
\hline \multirow[t]{2}{*}{ Sparkling shiraz } & -0.038 & -0.032 & 0.076 & 0.021 & -0.067 \\
\hline & $(0.48)$ & $(0.36)$ & $(2.60)$ & $(0.06)$ & $(1.65)$ \\
\hline \multirow[t]{2}{*}{ Sparkling white } & 0.064 & $0.104^{\star \star}$ & -0.014 & 0.040 & $0.079^{\star \star \star}$ \\
\hline & (2.39) & (5.26) & $(0.84)$ & $(0.45)$ & (7.36) \\
\hline
\end{tabular}

***, **, * denotes statistically significant at the 1, 5 and $10 \%$ levels respectively. Estimates evaluated at means of data. Robust $F$ statistics reported in parentheses, distributed as $\mathrm{F}(1, \mathrm{n}-29)$.

There appears to be reasonable consistency in the identification of price premiums or discounts across years for the specific types. Three wine types have predominately positive price impacts: blanc de blancs (10 years), sparkling white (nine years) and sparkling red (nine years). Four wine types have predominately negative estimates across years: prosecco (10 years), chardonnay/pinot noir (10 years), rosé (nine years) and cuvée (nine years). Sparkling shiraz with six positive estimates and brut with six negative estimates, exhibit no persistent price premium or discount pattern.

In terms of systematic trends in yearly estimates over time, only three wine types exhibit significant linear time trends. Sparkling red (0.015, linear time trend coefficient) and brut (0.013) exhibit increases in their impacts over time, that is, the price premiums for sparkling red and brut have increased over time. Prosecco $(-0.017$, linear time trend coefficient) exhibits increasingly negative marginal 
Table 8: Total sparkling wine type effect on prices: 2015-2019.

\begin{tabular}{|c|c|c|c|c|c|c|}
\hline & 2015 & 2016 & 2017 & 2018 & 2019 & 2010-2019 \\
\hline \multirow[t]{2}{*}{ Blanc de blancs } & $0.156^{*}$ & 0.105 & $0.086^{\star \star}$ & $0.106^{\star \star}$ & 0.043 & $0.108^{\star \star \star}$ \\
\hline & $(3.67)$ & $(4.14)$ & $(4.22)$ & $(4.66)$ & $(0.94)$ & $(47.6)$ \\
\hline \multirow[t]{2}{*}{ Brut } & $0.126^{\star \star}$ & -0.022 & 0.029 & 0.061 & 0.090 & $0.031^{*}$ \\
\hline & (4.98) & $(0.13)$ & $(0.28)$ & $(1.10)$ & $(1.80)$ & $(3.32)$ \\
\hline \multirow[t]{2}{*}{ Chardonnay pinot noir } & -0.014 & -0.019 & -0.049 & -0.051 & $-0.135^{\star \star}$ & $-0.045^{\star * \star}$ \\
\hline & $(0.06)$ & $(0.23)$ & $(2.28)$ & $(1.34)$ & (4.23) & $(12.3)$ \\
\hline \multirow[t]{2}{*}{ Cuvée } & -0.044 & $-0.120^{\star \star}$ & 0.052 & $-0.104^{\star \star}$ & -0.058 & $-0.054^{\star}$ \\
\hline & $(1.06)$ & $(6.39)$ & $(1.40)$ & (5.38) & $(1.65)$ & $(12.4)$ \\
\hline \multirow[t]{2}{*}{ Prosecco } & $-0.087^{\star}$ & $-0.110^{\star \star \star}$ & $-0.134^{\star \star \star}$ & $-0.204^{\star \star \star}$ & $-0.222^{\star \star \star}$ & $-0.137^{\star \star \star}$ \\
\hline & (3.74) & (11.6) & (18.2) & $(23.9)$ & $(36.2)$ & $(81.5)$ \\
\hline \multirow[t]{2}{*}{ Sparkling red } & 0.083 & 0.098 & 0.026 & $0.175^{\star \star}$ & $0.226^{\star \star}$ & $0.089^{\star \star \star}$ \\
\hline & $(0.24)$ & $(1.73)$ & $(0.10)$ & $(6.23)$ & $(6.20)$ & (10.8) \\
\hline \multirow[t]{2}{*}{ Sparkling rosé } & -0.003 & $-0.125^{\star \star \star}$ & 0.011 & -0.005 & -0.021 & $-0.049^{\star \star \star}$ \\
\hline & $(0.01)$ & $(8.64)$ & $(0.04)$ & $(0.02)$ & $(0.12)$ & (7.16) \\
\hline \multirow[t]{2}{*}{ Sparkling shiraz } & 0.073 & 0.024 & 0.059 & -0.044 & 0.082 & 0.027 \\
\hline & $(0.40)$ & $(0.16)$ & $(1.56)$ & $(0.51)$ & $(2.08)$ & (2.73) \\
\hline \multirow[t]{2}{*}{ Sparkling white } & 0.054 & $0.048^{\star}$ & 0.027 & 0.031 & 0.050 & $0.044^{\star \star \star}$ \\
\hline & $(1.71)$ & $(4.03)$ & (1.16) & $(0.97)$ & (1.86) & (19.5) \\
\hline
\end{tabular}

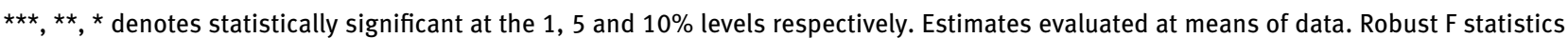
reported in parentheses, distributed as $F(1, n-29)$. Estimates for pooled data (2010-2019) include time dummies for year of release.

estimates over time, that is, the price discount for prosecco has increased over time.

In terms of statistical significance, two of the nine wine types have total impacts which are significant at least half the time: prosecco (seven years) and blanc de blancs (six years). The other important statistically significant impacts occur for cuvée (four years), sparkling red (three years) and sparkling white (three years).

The interaction effects between wine type and GDD class and wine type and cellar years from Tables 5 and 6 provide some interesting insights into the nature of the impact of sparkling wine type on prices. For the interaction with GDD class, the main statistically significant positive impacts are estimated for sparking shiraz (five years) and sparking red (three years). This implies that shiraz and reds are preferred by consumers and better suited for production in warm climates. In contrast, for GDD class interactions, the main statistically significant negative impacts are estimated for cuvée (five years), brut (three years) and chardonnay/pinot noir (three years). It appears that these wine types are better suited to cooler climates for the identified years.

For sparkling wine type interactions with cellar years the main statistically significant positive impacts are estimated for cuvée (four years) and processo (three years). This implies for these years, longer lived cuvée and processo wines reduce the price discounts for these wines. Interestingly, even though the bulk of processo wines are designed to be consumed immediately (65\% have non-positive cellar years), those wines with some cellar potential appear to be sought after and reduce the overall price discount for processo wines. The main statistically significant negative impacts for cellar year interactions are estimated for brut (four years) and sparkling shiraz (four years). Again the case of sparkling shiraz is interesting as even though most shiraz are designed to be cellared ( $77 \%$ have positive cellar years) those which have little or no cellar potential are preferred and add to any price premium for shiraz for the identified years.

The estimates in Tables 5 and 6 for the non-wine name/ type variables are as expected. The relation between quality ratings and prices is statistically and economically important for all years (except 2018) and averages 3.2\% per quality point (or $\$ 1.08$ per point at sample mean prices) across the individual year estimates. The GDD class variable is important for all years and averages $-7.8 \%$ per class (or $-\$ 2.63$ per class at sample mean prices). This confirms the importance of sparkling wines from cool climate regions attracting price premiums. Potential cellar years is statistically significant in seven of the 10 years, the average of yearly estimates is $3.8 \%$ for each additional cellar year (or \$1.28 per year at mean prices). Vintage years is statistically significant for all 10 years, the average of yearly estimates is $5.3 \%$ for each additional vintage year (or $\$ 1.79$ per year at mean prices). 


\section{Discussion and Conclusion}

This study has identified a number of important price premiums and discounts for specific types of Australian sparkling wines. The importance of sparkling wine type interactions with regional climatic conditions and cellaring potential on prices has also been established. These results point to some interesting findings.

The largest premiums are estimated for blanc de blancs and sparkling reds. Interestingly, blanc de blancs in Australia mainly use chardonnay as the grape varietal. Chardonnay winegrape prices tend to have higher prices than other white varieties (Wine Australia 2019). The use of the expression blanc de blancs rather than chardonnay on the label may be a consumer preference driven naming attribute commanding higher prices. Potentially, the importance of the use of the term blanc de blancs is another example of the Australian consumer preference for the use of French terms in wine labelling (Oczkowski 2018). It is noteworthy that a blanc de blancs premium is consistent with the Champagne study of Gergaud (1998) but contrary to some Bentzen and Smith (2008) Scandinavian results. Sparkling reds in our sample captures a series of relatively unique use of varietals in sparkling wine production such as merlot, petit verdot, durif, montepulciano and sangiovese. Here premiums could be consumer driven reflecting the relative uniqueness or exclusivity of these wines in the Australian market.

The largest sparkling wine price discount is estimated for prosecco. In Australia, prosecco is principally made using the tank based charmat method of production (Wine Selectors 2016) and hence the discounts in part may reflect the reduced costs of production.

Of the other estimated marginal impacts for wine types, it is of interest to note that the relatively unique (world-wide) sparkling shiraz commands close to average market prices. In Australia, shiraz is the most dominate red grape variety grown (Wine Australia 2019) and hence any uniqueness is potentially lost on the typical Australian consumer. Finally, the estimated moderate price discount $(-5.9 \%)$ for cuvée may seem counterintuitive as the name reflects the use of the highest quality grape juice and/or first pressings. In the Australian context the term appears not to lead to any additional price premiums and its impact may be more apparent through higher quality wines reflected in higher quality scores rather than the use of the name alone.

The estimates of the GDD class and cellar years interaction terms with sparkling wine type point to some interesting findings. In particular, it appears that some sparkling wine types (e.g. cuvée and brut) are better produced in cool climatic regions, while others (e.g. sparkling shiraz and sparkling reds) are better developed in warm climate regions. Interestingly, even though the bulk of processo wines are made for immediate consumption those which have some cellaring potential appear to reduce the overall price discount of processo. Similarly, even though the bulk of sparkling shiraz wines are designed to be long lived, those with no or short cellaring potential appear to positively add to the slight price premium for shiraz in some years.

Our results in general point the relative stability of the sign of the point estimates for premiums or discounts for many of the sparkling wine types over time. Seven of the nine styles have consistent premiums or discounts for at least nine of the 10 sampled years. However, some statistical instability is evident in estimates over time. In part this is due to the sampling variation in the assessed wines over time. The parameter instability is also possibly due to shifts in consumer preferences and/or the costs of producing different styles over time. In part the results are similar to Faye and Le Fur (2019) who found parameter instability in hedonic estimates for Bordeaux wines over time. An implication of the instability of estimates is that hedonic price estimates need to be continually updated and reliance on past short-term and long-term hedonic estimates may be misleading.

In conclusion, the estimated impacts potentially have important implications for producers who may wish to strategically use names on labels to gain higher prices or avoid lower prices. Also consumers could potentially avoid over priced wines which are estimated to have price premiums purely driven by naming conventions and not by what is inside the bottle. The employed hedonic price technique could potentially be used for other countries' sparkling wine markets and/or other specific wine styles where different wine types or names are commonly employed.

\section{References}

Anderson, K., S. Nelgen, and V. Pinilla. 2017. Global Wine Markets, 1860 to 2016: A Statistical Compendium. Adelaide: University of Adelaide Press.

Australian Bureau of Statistics (ABS). 2019. Consumer Price Index, Australia. ABS Cat no 6401.0. Canberra: ABS.

Bekkerman, A., and G. W. Brester. 2019. “Don't Judge a Wine by its Closure: Price Premiums for Corks in the U.S. Wine Market." Journal of Wine Economics 14: 3-25.

Bentzen, J., and V. Smith. 2008. "Do expert Ratings or Economic Models Explain Champagne Prices?." International Journal of Wine Business Research 20: 230-43.

Cardebat, J. M., and J. M. Figuet. 2004. "What Explains Bordeaux Wine Prices?.” Applied Economics Letters 11: 293-6.

Cardebat, J. M., J. M. Figuet, and E. Paroissien. 2014. “Expert Opinion and Bordeaux Wine Prices: An Attempt to Correct Biases in Subjective Judgments." Journal of Wine Economics 9: 282-303. 
Chambers, M. 2008. A Survey of Wine Grape Growing Farms in the Murray Valley and Barossa Regions, 2006-07. Canberra: ABARE Research Report 08.11 for the Australian Government Department of Agriculture, Fisheries and Forestry.

Charters, S. 2005. "Drinking Sparkling Wine: an Exploratory Investigation." International Journal of Wine Marketing 17: 54-68.

Combris, P., S. Lecocq, and M. Visser. 1997. "Estimation of a Hedonic Price for Bordeaux Wine: Does Quality Matter?." The Economic Journal 107: 390-402.

Culbert, J. A., R. Ristic, L. A. Ovington, A. J. Saliba, and K. L. Wilkinson. 2017. "Influence of Production Method on the Sensory Profile and Consumer Acceptance of Australian Sparkling White Wine Styles." Australian Journal of Grape and Wine Research 23: 170-8.

Faye, B., and E. Le Fur. 2019. "On the Constancy of Hedonic Wine Price Coefficients over Time.” Journal of Wine Economics 14: 182-207.

Ferro, G., and I. B. Amaro. 2018. "What Factors Explain the Price of Top Quality Wines?." International Journal of Wine Business Research 30: 117-34.

Gergaud, 0. 1998. "Estimation d'une fonction de prix hédonistiques pour le vin de Champagne.” Économie \& Prévision 136: 93-105.

Hall, A., and G. V. Jones. 2010. "Spatial Analysis of Climate in Winegrape-Growing Regions in Australia." Australian Journal of Grape and Wine Research 16: 389-404.

International Organisation of Vine and Wine Intergovernmental Organisation (OIV). 2019. Statistical Report on World Vitivinculture. Paris: OIV.

Kennedy, P. E. 1986. “Interpreting Dummy Variables.” The Review of Economics and Statistics 68: 174-5.

Lee, H., and D. A. Sumner. 2013. "The Economic Value of Wine Names that Reference Place in the US Market: Analysis of 'Champagne' and Sparkling Wine." In Wine Economics: Quantitative Studies and Empirical Applications, edited by E. Giraud-Heraud and M-C. Pichery, ch 4, 73-87. Houndmills, UK: Palgrave Macmillian. Lima, T. 2006. "Price and Quality in the California Wine Industry: An Empirical Investigation.” Journal of Wine Economics 1: 176-90.

Ling, B.-H., and L. Lockshin. 2003. "Components of Wine Prices for Australian Wine: How Winery Reputation, Wine Quality, Region,
Vintage, and Winery Size Contribute to the Price of Varietal Wines." Australasian Marketing Journal 11: 19-32.

Oczkowski, E. 1994. "A Hedonic Price Function for Australian Premium Table Wine." Australian Journal of Agricultural Economics 38: 93-110.

Oczkowski, E. 2010. "Hedonic Wine Price Predictions and Non-normal Errors.” Agribusiness: International Journal 26: 519-35.

Oczkowski, E. 2016a. "The Effect of Weather on Wine Quality and Prices: An Australian Spatial Analysis.” Journal of Wine Economics 11: 48-65.

Oczkowski, E. 2016b. "Identifying the Effects of Objective and Subjective Quality on Wine Prices." Journal of Wine Economics 11: 249-60.

Oczkowski, E. 2018. "The Impact of Different Names for a Wine Variety on Prices." International Journal of Wine Business Research 30: 185-200.

Oczkowski, E., and H. Doucouliagos. 2015. "Wine Prices and Quality Ratings: A Meta-Regression Analysis." American Journal of Agricultural Economics 97: 103-21.

Oliver, M., S. Hooper, W. Gordon, and D. Galeano. 2006. McLaren Vale and Riverina Regions: A Survey of Wine Grape Producers, 200304 and 2004-05. ABARE Research Report 06.14 Prepared for the Grape and Wine. Canberra: Research and Development Corporation.

Outreville, J-F., and E. Le Fur. 2020. "Hedonic Price Functions and Wine Price Determinants: A Review of Empirical Research." Journal of Agricultural \& Food Industrial Organization, https://doi.org/10. 1515/jafio-2019-0028 (Epub ahead of print).

Schamel, G., and K. Anderson. 2003. "Wine Quality and Varietal, Regional and Winery Reputations: Hedonic Prices for Australia and New Zealand." The Economic Record 79: 357-69.

Wine Australia. 2019. National Vintage Report 2019. Adelaide: Wine Australia.

Wine Selectors. 2016. "Following the Prosecco Road - Your Guide to Australian Prosecco." Selector Magazine. 17 Dec. Also available at https://www.wineselectors.com.au/selector-magazine/ wine/australian-prosecco-infographic-guide. 